\title{
Perception of Aging Among Nursing Students
}

\author{
Ozlem Sinan' (1), Naile Bilgili² (1), Aysun Mutlu² (1) \\ 'Department of Nursing, Ankara Yıldırım Beyazıt University, Faculty of Health Sciences, Ankara, Turkey \\ ${ }^{2}$ Department of Nursing Gazi University, Faculty of Health Sciences, Ankara, Turkey
}

ORCID iDs of the authors: O.S. 0000-0002-7620-3897; N.B. 0000-0002-7639-0303; A.M. 0000-0003-4I00-3067.

Cite this article as: Sinan O, Bilgili N, Mutlu A. Perception of Aging Among Nursing Students. Cyprus J Med Sci 202I; 6(I): 80-5.

\section{BACKGROUND/AIMS}

The perception of aging by health professionals who serve the older people affects the quality of care; hence, this study aimed to identify nursing students' perception of aging.

\section{MATERIAL and METHODS}

This descriptive study by the nursing faculty of two different state universities included 543 nursing students who showed willingness to participate. For data acquisition, a questionnaire was provided to the study participants; the questionnaire included the students' sociodemographic features and their perception of aging. The data were assessed using numbers, percentages, mean \pm standard deviation values, and the chi-square statistical test.

\section{RESULTS}

The mean age of the students was $22.00 \pm 1.20$ years, and $88.8 \%$ were female. Most of the students agreed with the concept that in older individuals, "cognitive skills take a turn for the worse and learning ability is lost" (79.4\%). Assessments of the students showing care for older individuals indicated that the students tended to be more patient with older individuals ( $94.5 \%$ ). Gender and the students' academic level affected their perception of aging.

\section{CONCLUSION}

The study results found that nursing students' perceptions of older individuals were positive; however, certain perspectives and behaviors toward provision of care to older people were negative.

Keywords: Aging, nursing, students, perception

\section{INTRODUCTION}

The aging of the world population is one of the most important challenges of the $2{ }^{15 t}$ century. In several countries, the number of older individuals and the rate of increase in the aging proportion have reportedly surged (I). Turkey is one of the countries experiencing this demographic transformation, with a rapidly aging population. The older individual population presently constitutes $8.5 \%$ of the total population in Turkey. The life expectancy is 75.3 years for men and 80.7 years for women (2). A striking phenomenon related to the increasing older population in Turkey is that the specific population of people aged 7580 years continues to increase. The increase in the aging population impacts all aspects of the society, ranging from social safety, education, and job opportunities to family life, along with the burden placed on the health system. Aging is an area of special importance, and it is necessary for health professionals to provide solutions to the specific health care needs of the older population. Nursing is a crucial profession in which health care is provided to the aging population. Geriatric nursing is rapidly developing as an area of expertise; however, special knowledge, ability, and talent are prerequisites for nurses to provide efficient geriatric nursing services $(3,4)$. The current demographic changes, together with the increased need for high-quality health care services, pose challenges for nurses in the provision of care to aging individuals (5).

Attitudes about old age and older individuals, prejudices, and beliefs impact decision-making and behaviors toward older individuals. Attitudes toward the older individual shape and influence the behavior of health professionals and the quality of the care provided to the older individual $(6,7)$. Studies have shown that the nursing students identified as members of the young group act in a prejudiced manner toward older individuals because of a lack of general in- 
formation, negative myths, and stereotyped attitudes (8-10). Negative myths and attitudes may negatively affect the care provided to older individuals (I0). Certain studies have shown that nursing students believe that health professionals demonstrate negative attitudes toward aging individuals (II, 12). These attitudes affect the quality of nursing care provided to the older individual and may ultimately dissuade caregivers from obtaining sufficient information concerning older individuals, thus neglecting their autonomy or integrity, and jeopardizing their dignity (13-15). Eltantawy (16) has reported that nursing students harbor prejudice regarding the care of older individuals for the past 30 years. Nurses have demonstrated less desire to work in geriatric clinics and nursing homes, and show inclination to work with pediatric or adult patients (16). The quality of nursing care provided to older individuals depends on how education is imparted to nursing students and how nursing students are prepared for providing nursing service. Adebusoye et al. (12), Eltantawy (16), and Oyetunde et al. (17) have reported that nurses' attitudes and behaviors toward the aging population affect their expectations regarding working life and their approach toward their patients $(12,16,17)$. The increase in the proportion of the older population and the concomitant chronic illnesses associated with aging cause decreased physical functionality and increased dependency; hence, correct attitudes of nurses, sufficient working knowledge, and skills for providing geriatric care should be emphasized. Owing to the above-mentioned issues, the perceptions of nurses (who provide care to older individuals) on aging and older individuals must be identified.

\section{MATERIALS and METHODS}

\section{Study Sample}

This study comprised 570 students who were second-, third-, and fourth-year students tutored by the nursing faculty of two state universities in Ankara, Turkey. As first-year students possess less knowledge and expertise, they were not included. In this study, sample selection was not conducted, and the study was targeted to reach all students who received instructions during April-May 2017. The final sample comprised 543 students who agreed to participate (95.0\%).

\section{Data Collection Tools}

Information on the sociodemographic status of the students and their views and perceptions on aging was assessed using a questionnaire $(8,10,13,15,18)$. The questionnaire was also used to gather information regarding the students' behaviors while providing nursing care services to older individuals. The questions were developed by researchers after conducting a literature re-

\section{Main Points:}

- Negative myths and attitudes may negatively impact the care provided to older individuals.

- The manner in which education is imparted to nursing students to prepare them for providing nursing services may influence their perceptions of aging and the aging population.

- Educational activities must be planned to change the negative perceptions and attitudes and to create awareness among nursing students about the aging process. view aimed at determining the perception of nursing students on aging. These questions were not an inventory; hence, total score was not calculated.

\section{Ethical Considerations}

Ethics committee approval was obtained from Ankara Yıldırım Beyazit University Ethics Committee (31.03.2017/06). Participants were provided with verbal and written information about the purpose of the study and were provided with the opportunity to raise queries.

\section{Data Collection}

After obtaining ethical approval and official permission for the conduction of the study, the investigators informed the students about the study aspects in a classroom and invited interested students for participation. Questionnaires were provided to the students 15 minutes before the commencement of lectures and were collected after complete responses were received.

\section{Statistical Analysis}

Data were assessed using the Statistical Package for the Social Sciences 16 program (IBM SPSS Corp.; Armonk, NY, USA) using numbers, percentages, mean \pm standard deviation values, and the chi-square statistical test. For the present study, $p<0.05$ was considered statistically significant.

\section{RESULTS}

The mean age of the students was $22.00 \pm 1.20$ years, and $88.8 \%$ students were female. Among the study participants, $23.9 \%$ were second-year students, $33 \%$ were third-year students, and $42 \%$ were fourth-year students. Regarding questions on living conditions, $51 \%$ of all the participants indicated that they were living with their grandmother or grandfather. Responses indicated that the majority of the students (83.1\%) gained experience in providing care to older individuals during their clinical practices (Table I).

\begin{tabular}{|c|c|c|}
\hline Demographics & Number $(n)$ & Percentage (\%) \\
\hline \multicolumn{3}{|c|}{ Nursing school level } \\
\hline Second year & 130 & 23.9 \\
\hline Third year & 179 & 33.0 \\
\hline Fourth year & 228 & 42.0 \\
\hline \multicolumn{3}{|l|}{ Sex } \\
\hline Female & 482 & 88.8 \\
\hline Male & 61 & 11.2 \\
\hline \multicolumn{3}{|c|}{ Age (mean: $22.00 \pm 1.20$ years) } \\
\hline $20-25$ years & 538 & 98.4 \\
\hline$>25$ years & 3 & 0.6 \\
\hline \multicolumn{3}{|c|}{ Living with people aged $\geq 65$ years } \\
\hline Yes & 277 & 51.1 \\
\hline No & 265 & 48.9 \\
\hline \multicolumn{3}{|c|}{ Provision of care to older individuals in clinical settings } \\
\hline Yes & 451 & 83.1 \\
\hline No & 91 & 16.8 \\
\hline
\end{tabular}


The study results showed that the students associated the word aging with terms like illness (59.5\%), compassion (56.7\%), and weakness (47.5\%) (Table 2) upon hearing the word aging. Among the participants, $35.4 \%$ declared that they preferred to spend time with young patients rather than with older patients; additionally, $21.2 \%$ of the participants declared that they preferred to explore solutions for issues in young patients rather than for

\begin{tabular}{|c|c|c|}
\hline Concepts/terms & Number (n) & Percentage(\%)** \\
\hline Illness & 323 & 59.5 \\
\hline Compassion & 305 & 56.7 \\
\hline Weakness & 258 & 47.5 \\
\hline Dependence & 189 & 34.8 \\
\hline Wisdom & 175 & 32.2 \\
\hline Loneliness & 174 & 32.0 \\
\hline Dependency & 162 & 29.8 \\
\hline Mental decline & 62 & II. 4 \\
\hline Happiness & 31 & 5.7 \\
\hline Depression & 21 & 3.9 \\
\hline Poverty & 19 & 3.5 \\
\hline Sloppiness & 19 & 3.5 \\
\hline İsolation & 15 & 2.8 \\
\hline Independence & 13 & 2.4 \\
\hline Ugliness & $\|$ & 2.0 \\
\hline Political power & 9 & 1.7 \\
\hline Abundance & 7 & 1.3 \\
\hline
\end{tabular}

those in older patients. Regarding responses for communication with older patients, $35.4 \%$ of the students expressed that they provided simplified information and mimicked baby talk when providing information to older patients; furthermore, $88.8 \%$ of the students were more respectful to the older patients, $88.4 \%$ of students were more respectful because of older patients' cultural characteristics, $17.5 \%$ of the students were wary of older patients, $54.7 \%$ of the students preferred to share information about the older patient's relatives, and almost all students were more patient (tolerant) with older patients (Table 3 ).

Regarding the nurses' perceptions of older persons, we observed that $63.2 \%$ agreed with the statement " $60-65$ years of age means senility," $54.5 \%$ agreed with the statement "the aging period refers to inability and a period of illness," and 79.4\% agreed with the idea that "cognitive skills take a turn for the worse and learning ability is lost." As shown in Table 4, most of the students did not agree with certain ideas, such as, "Old people demonstrate self-pity, and are unfeeling, bad-tempered, grumpy, and constantly complaining" (86.7\%), "All old people are alike" (84.0\%), "The memory of older people is weak, and almost all of them are dotards" (79.7\%), "Older individuals are less active" (79.2\%), and "Old people are abandoned and alone, and they cannot pursue activities" (70.9\%). Other statements that most of the students did not agree with included "Older people are not interested in sexuality, and interest in sexuality is inconvenient" (82.5\%), "Most older people are unhappy and do not get pleasure from life" (75.7\%), "Sexuality is not important during the senility period" (74.4\%), and "As the individuals are approaching the end of life, provision of special health care is not necessary; moreover, these services are not helpful" (91.0\%).

The students' sex and graduation year $(p<0.05)$ affected their perception of old age. Female students' perception was more favorable (positive) than that of male students. The higher the curriculum level, the more positive the perception of old age; for

TABLE 3. Students' perspectives on the provision of care to older individuals

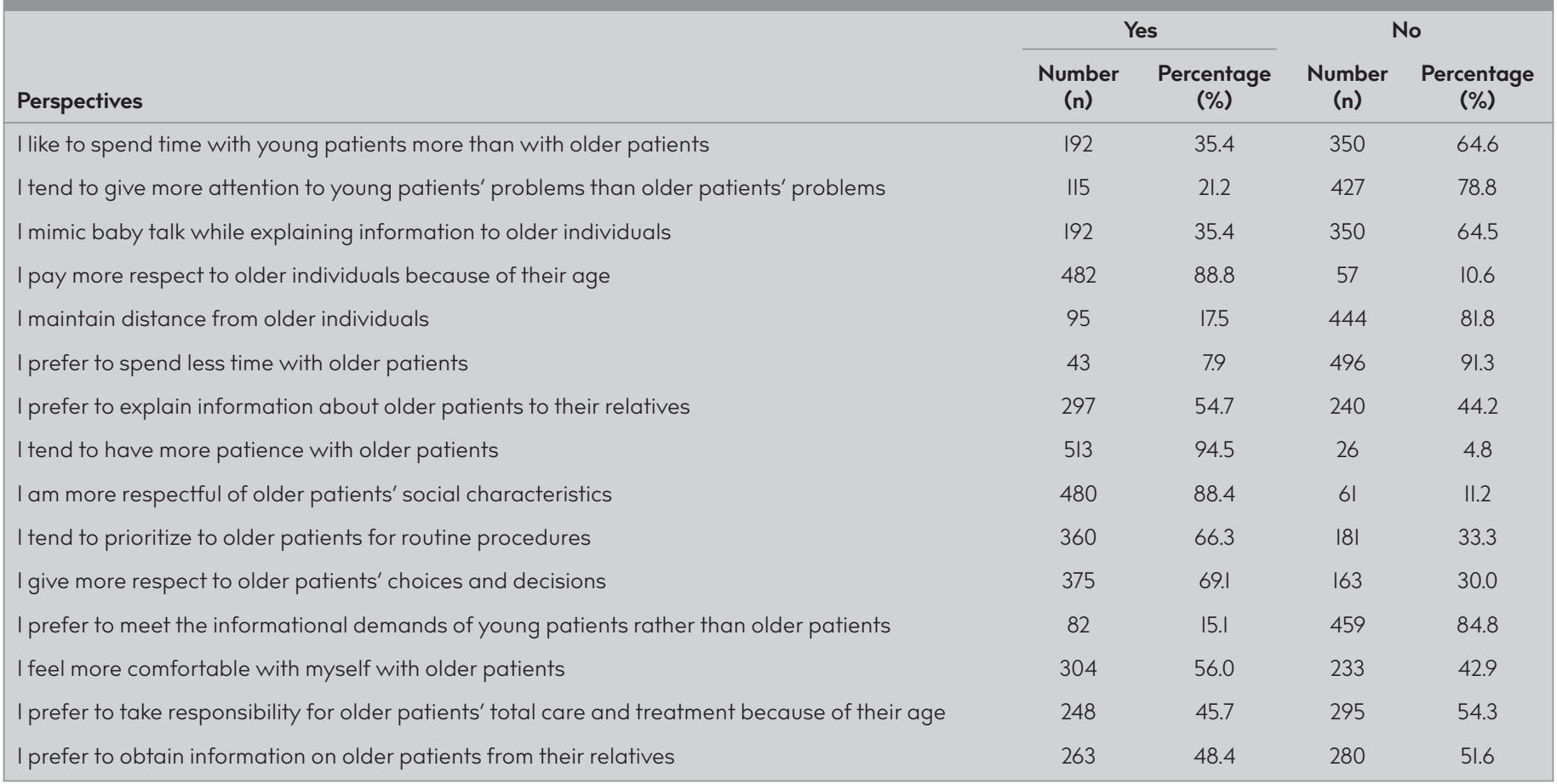


TABLE 4. Students' perspectives about aging and older individuals

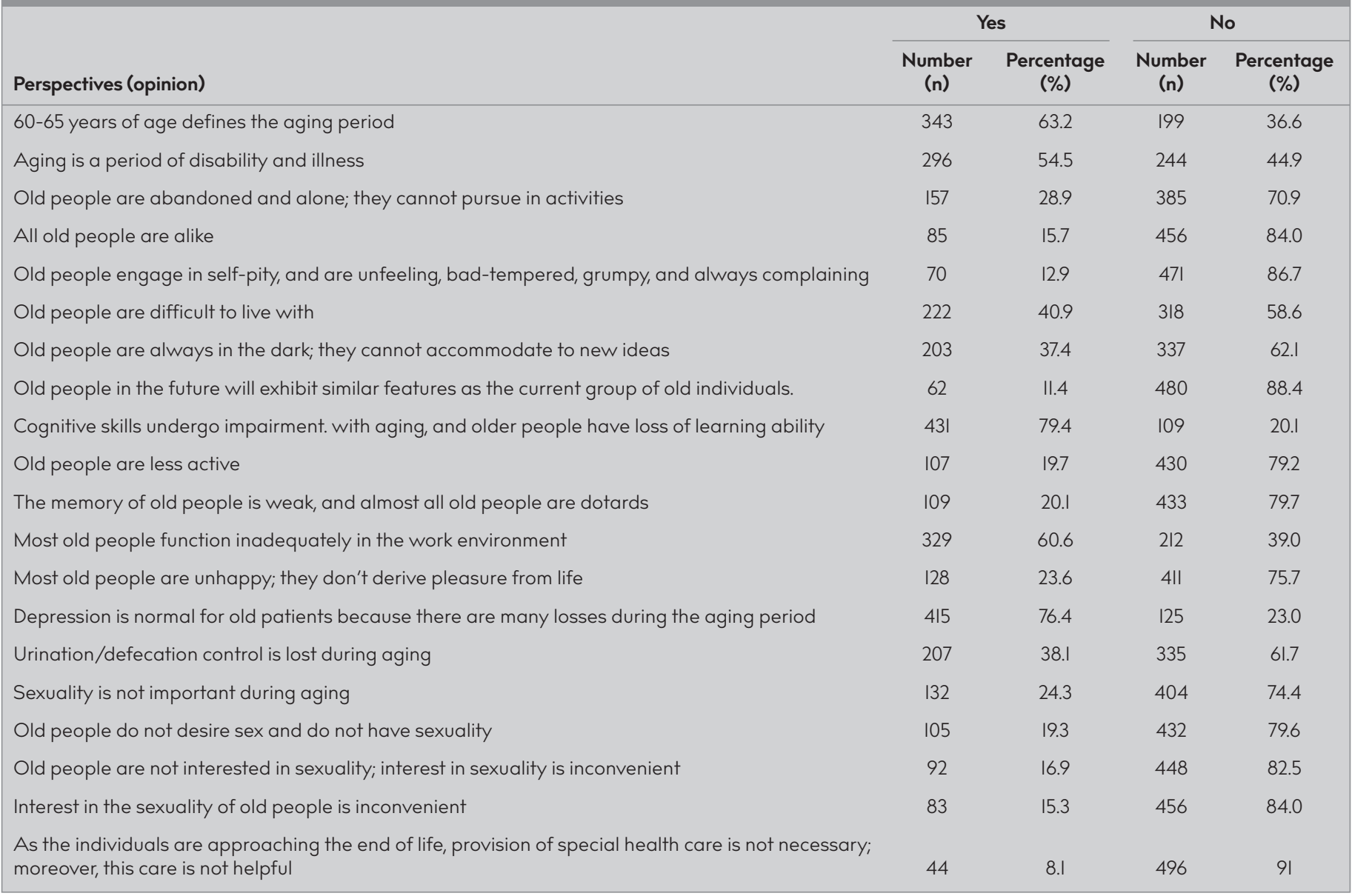

example, fourth-year students' perception was more positive (favorable) than that of second-year students.

\section{DISCUSSION}

As the population of older people continues to increase, nurses play an important role in the health care system and are expected to play a more vital role in providing health care for older people. Therefore, the assessment of nurses' perceptions and perspectives on aging and on the provision of care to older individuals is important for the expanding geriatric population in terms of healthy aging.

Based on the recent advancements in the knowledge of the aging process with respect to physical and social changes, old age has been evaluated in two ways, namely positive and negative. An example of the positive evaluation is that older people are wise, are experienced, have high social status, are worthy of utmost respect, and exert an influence on others. An example of the negative evaluation is that aging is a weakness (deficiency) and that it results in irreversible losses (19). Certain myths or stereotyped phrases are described as features shared by the members of certain social groups, and the myths or stereotypes have shaped beliefs about typical behaviors or attitudes (19). When associated with positive or negative connotations and thoughts or beliefs about aging and old age, attitudes that lead to discriminatory behavior or prejudice toward members of a particular group can potentially emerge. The negative myths surrounding the stereotypes of old age-myths of physical and mental disability-are based on the belief that old age is synonymous with disease. This belief and the resulting myths are maintained by negative stereotypes in society at large and in various age groups (20).

In this study, the assessment of students' views on older people mostly focused on the physiologic and cognitive changes associated with aging. The most common perceptions include the following: aging is synonymous with illness, older people are weak, mental abilities decline with aging and learning ability is lost, depression is normal in older people because there are losses in the aging period, older individuals are alone and it is impossible for them to pursue activities, and most older people function inadequately in the working environment. These results showed that the study participants had certain stereotypical thoughts and myths and that there are a few topics about the aging process on which awareness should be generated among nursing students. The students' perceptions and perspectives may have been influenced by general misinformation in the society, and this misinformation can pose risks for older people.

Studies have shown that the provision of health care to older people is not a common practice among nursing students (21, 22). This practice is associated with factors of the perception of old age, attitudes, work experience, and trouble in the work environment $(23,24)$. Attitudes toward older individuals shape the healthcare delivery behavior of healthcare professionals and exert a direct impact on the quality of care provided to older 
people $(6,7)$. In studies that involved nursing students, two types of attitudes-appreciation of older people and prejudice against them-have been reported $(8,24,25)$. An appreciative attitude is related to the understanding of older individuals, and prejudice is associated with discriminatory thoughts on the rights of the aging individuals or an inability to realize the needs of the aging individuals $(8,24)$.

This study found that the majority of participants believed that older people are sensitive and require special attention and that older people deserve respect and appreciation. The students did not support prejudice toward the older people.

Ünsar et al. (26) have reported that students have positive faith and perception. Özdemir and Bilgili (18) have declared that nursing students have a positive attitude toward the older individuals (18). However, Frost et al. (27) and Van Leeuwen et al. (28) have claimed that students have a negative attitude to the aging population.

Studies that have evaluated nursing students' attitudes, perspectives, and perceptions of the older individuals have indicated that gender is an important factor; female students have a more positive attitude toward the older individuals than male students (25, $29,30)$. The probable reason is that women consider their cultural care role seriously. Our study results are similar to those reported in literature and show that male students are more unfriendly toward older patients than female students and that they do not develop a close relationship with older patients. Male students tend to believe that older people are less active and that special health services are not necessary for them.

Education is the most important factor in changing the professional attitude of nursing students toward the aging individuals (24). Upper-class level (third-year or fourth-year) nursing students are expected to exhibit a more positive attitude for gaining understanding and knowledge of the needs of the aging population because these students have received more information about geriatrics and gerontology (3l). Strugala et al. (3I) have suggested that there exists a relationship between the educational level and the attitudes of nursing students. Additional factors that may negatively influence a nurse's behavior toward older patients are those not directly related to old age, for example, attending evening school while working to obtain additional education; difficult working conditions of nurses in some countries, such as those in Poland; heavy workloads; or experiencing burnout. Hanson (32) has reported that both nursing students and professional nurses exhibit negative attitudes toward the aging individuals at certain instances, the most important cause being the lack of information about the aging process. Studies by Hweidi and Al-Obeisat (9) also support a relationship between education and attitudes. Ünsar et al. (18) and Özdemir and Bilgili (26) found that fourth-year students' behavior toward old people was more positive. Similar studies produced similar results and showed that upper-class students' attitudes toward the aging population were more positive (2l, 33). Our study results supported similar results because the students of the highest level of medical school curriculum (fourthyear students) were observed to exhibit negative attitudes toward aging and the aging process in some cases; however, they generally exhibited a positive attitude.
If students live with an older individual at home, the students may establish a good emotional connection with the older individuals and may prefer to spend more time with them. It is thought that through this daily interaction, these students begin to holistically understand the aging process and develop positive perspectives toward aging and the aging process. Several authors have stated that living with older people in the same home and establishing a close emotional connection at home affects attitudes and feelings toward the aging population (34, 35). Bulut et al. (18) and Özdemir and Bilgili (36) showed that students who share good relationships with their grandmother and grandfather have a more positive attitude toward the aging population.

In clinical settings, students who provide health care to older individuals share increased emotional connections with the older individuals and gain positive perceptions of aging. Studies similar to ours have reported that students who have gained clinical experience with older individuals harbor more positive thoughts toward them $(9,37)$.

The increasing population of older individuals poses challenges for the healthcare system and for the nurses who have been entrusted with duties of providing first-line care for the aging population. Nurses' attitudes and perceptions on aging affect the quality of care. Therefore, awareness of nurses' and nursing students' attitudes and perceptions of older people and of the aging process is important. An investigation into the myths and stereotypes that influence these attitudes is also crucial. Avoidance of prejudice and stereotypes and the development of positive perceptions by nurses and nursing students are important for increasing the quality of care and increasing older individuals' satisfaction with the care provided. Our study results show that nursing students generally have a positive perception of the aging population; however, certain opinions and behaviors toward service delivery are negative. For this reason, activities must be planned to impart education on the aging process, to change the negative perceptions and attitudes toward aging and aged individuals, and to create awareness among health professionals (nurses) and in the society.

Ethics Committee Approval: Ethics committee approval was received for this study from the ethics committee of Ankara Yıldırım Beyazıt University (31.03.2017/06).

Informed Consent: All participants received oral information on all aspects of the study and verbal informed consent was obtained from students who participated in this study.

Peer-review: Externally peer-reviewed.

Author contributions: Concept - O.S., N.B.; Design - O.S., N.B.; Supervision - O.S., N.B., A.M.; Resource - O.S., N.B., A.M.; Materials - O.S., N.B., A.M.; Data Collection and/or Processing - O.S., N.B., A.M.; Analysis and/or Interpretation - O.S., N.B., A.M.; Literature Search - O.S., N.B., A.M.; Writing - O.S., N.B., A.M.; Critical Reviews - O.S., N.B., A.M.

Conflict of Interest: The authors have no conflicts of interest to declare.

Financial Disclosure: The author declared that this study has received no financial support. 


\section{REFERENCES}

I. United Nations, 2015. Department of Economic and Social Affairs Population Division: World Population Ageing 1950-2050. [Cited 2 January 2019]. Available from URL: http://www.un.org/en/development/desa/population/publications/pdf/ageing/WPA2015_ Report.pdf

2. Turkey Statistical Institute (TSI) (2018). Elderly with statistics, 2017. [Cited 2 January 2019]. Available from URL: http://www.tuik.gov.tr/ PreHaberBultenleri.do?id=I5844.

3. Ferreira VM, Ruiz T. Community health workers' attitudes and beliefs toward the elderly. Rev Saude Publica 2012; 46(5): 843-9. [Crossref]

4. Faronbi JO, Adebowale O, Faronbi GO, Musa OO, Ayamolowo SJ. Perception knowledge and attitude of nursing students towards the care of older patients. International Journal of Africa Nursing Sciences 2017; 7: 37-42. [Crossref]

5. King BJ, Roberts TJ, Bowers BJ. Nursing student attitudes toward and preferences for working with older adults. Gerontol Geriatr Educ 2013; 34(3): 272-91. [Crossref]

6. Jacelon CS. Attitudes and behaviors of hospital staff toward elders in an acute care setting. Appl Nurs Res 2002; 15(4): 227-34. [Crossref]

7. McLafferty I, Morrison F. Attitudes towards hospitalized older adults. Journal of Advanced Nursing 2004; 47(4): 446-53. [Crossref]

8. Lambrinou E, Sourtzi P, Kalokerinou A, Lemonidou C. Attitudes and knowledge of the Greek nursing students towards older people. Nurse Educ Today 2009; 29(6): 617-22. https://doi.org/10.1016/i. nedt.2009.01.0II.

9. Adıbelli D, Türkoğlu N, Kılıç D. Views of Nursing Students About Ageing and Their Attitudes Toward Older People. Dokuz Eylul University E-Journal of Nursing Faculty 2013; 6(I): 2-8.

10. Doherty M, Mitchell EA, O’Neill S. Attitudes of healthcare workers towards older people in a rural population: A survey using the Kogan Scale. Nurs Res Pract 20II; 20II: 352627. [Crossref]

II. Alsenany S. Student nurses' attitudes and knowledge towards the care of older people in Saudi Arabia. Generations Review British Geriatrics Society 2009. https://sos.kau.edu.sa/Files/0004020/Researches/60175_32558.pdf.

12. Oyetunde MO, Ojo OO, Ojewale LY. Nurses' attitude towards the care of the elderly: Implications for gerontological nursing training. Journal of Nursing Education and Practice 2013; 3: 150. [Crossref]

13. Erdemir F. Aging and old age beliefs and attitudes. In: Bilgili, N., $\bar{\alpha}$ Kitiș, Y. (Eds.), Ageing and Elderly Health. Ankara, Turkey: Visa Press Release: 33-44, 2017.

14. Kagan SH, Melendez-Torres GJ. Ageism in nursing. J Nurs Manag 20I5; 23(5): 644-50. [Crossref]

15. Özdemir Ö, Bilgili N. Ageism in health care. Gülhane Medical Journal 2014; 56: 128-31. [Crossref]

16. Eltantawy SHA E. Relation between nursing students' knowledge of aging and attitude towards elderly people and their will and intent to work with the elderly. Journal of Education and Practice 2013; 4.

17. Adebusoye L A, Ladipo MM, Owoaje ET, Ogunbode AM. Morbidity pattern amongst elderly patients presenting at a primary care clinic in Nigeria. African Journal of Primary Health Care $\delta$ Family Medicine 20II; 3: 2II. [Crossref]

18. Özdemir Ö, Bilgili N. Attitudes of Turkish nursing students related to ageism. J Nurs Res 2016; 24(3): 211-6. [Crossref]
19. Sarabia-Cobo CM, Castanedo Pfeiffer C. Changing negative stereotypes regarding aging in undergraduate nursing students. Nurse Educ Today 2015; 35(9): e60-4. [Crossref]

20. Meisner BA. A meta-analysis of positive and negative age stereotype priming effects on behavior among older adults. J Gerontol B Psychol Sci Soc Sci 2012; 67(I): 13-7. [Crossref]

21. Demiray T, Yılmaz DÜ. Opinions of the nursing students on ageism. İstanbul Medical Journal 2017; 18: 7-12. [Crossref]

22. McCann TV, Clark E, Lu S. Bachelor of Nursing students career choices: a three-year longitudinal study. Nurse Educ Today 20I0; 30(I): 31-6. [Crossref]

23. Gallagher S, Bennett KM, Halford JC. A comparison of acute and long-term health-care personnel's attitudes towards older adults. Int J Nurs Pract 2006; 12(5): 273-9. [Crossref]

24. Holroyd A, Dahlke S, Fehr C, Jung P, Hunter A. Attitudes toward aging: implications for a caring profession. J Nurs Educ 2009; 48(7): 374-80. [Crossref]

25. Pan IJ, Edwards $H$, Chang A. Taiwanese nursing students' attitudes toward older people. J Gerontol Nurs 2009; 35: 50-5. [Crossref]

26. Ünsar S, Özgül E, KurtS, Türüng F, Sekmen DI, Sak C, et al. Evaluation of ageism attitudes of nursing students. Cumhuriyet Nurs J 2015; 4: 61-7.

27. Frost J, Ranse K, Grealish L. Assessing ageist behaviours in undergraduate nursing students using the Relating to Older People Evaluation (ROPE) survey. Australas J Ageing 2016; 35(I): 58-6l. [Crossref]

28. Van Leeuwen E, Oosterhuis M, Ruyter S. Anxiety and categorisation effects in student nurses' attitudes towards young and older patients: A dual pathway model. Nurse Educ Today 2016; 39: 170-5. [Crossref]

29. Bernardini Zambrini DA, Moraru M, Hanna M, Kalache A, Nuñez JFM. Attitudes toward the elderly among students of health care related studies at the University of Salamanca, Spain. J Contin Educ Health Prof 2008; 28(2): 86-90. [Crossref]

30. Usta $Y Y$, Demir $Y$, Yönder M, Yildiz A. Nursing students' attitudes toward ageism in Turkey. Arch Gerontol Geriatr 2012; 54(I): 90-3. [Crossref]

31. Strugala M, Talarska D, Wysocki J. Attitudes towards the elderly among nursing students in Poland - Initial findings. J Gerontol Geriatr Res 2016; 5(I). [Crossref]

32. Hanson RM. 'Is elderly care affected by nurse attitudes?' A systematic review. Br J Nurs 20l4; 23(4): 225-9. [Crossref]

33. Koç $A$, Yıldırım R, Gürcü M, Uluçay DV. Assessing young university students' behaviour regarding age discrimination. The Annals of Eurasian Medicine 20I3; I: 49-55. [Crossref]

34. Yeșilot BS, Demirci YP, Öztunç G. Determination of Nursing Students' Attitudes Towards Elderly Discrimination and Affecting Factors. Journal of Duzce University Health Sciences Institute 2020; IO(I): 87-93.

35. Wu LL. A cross-sectional survey of student nurses' attitudes and knowledge about older people. Chinese Journal of Gerontology 20Il; 31: 848-50.

36. Bulut E, Cilingir D, Hintistan S. Attitudes of nursing students towards ageism. Dokuz Eylul University Nursing Faculty Electronic Journal 2017; 10: 137-43. [Crossref]

37. Altay B, Aydın T Evaluation of the attitudes of nursing students towards ageism. Journal of Education and Research in Nursing 2015; 12: II-8. [Crossref] 